\title{
PRODUCTION INVENTORY MODEL FOR CONTROLLABLE DETERIORATION RATE WITH SHORTAGES
}

\author{
Umakanta Mishra $^{1,2}$, Jacobo Tijerina-Aguilera ${ }^{1}$, Sunil Timari ${ }^{3}$ \\ ANd LEOPOLdo EduARdo CÁRdENAS-BARRÓN ${ }^{4, *}$
}

\begin{abstract}
This paper deals with an economic production quantity (EPQ) inventory model for deteriorating items under preservation technology. The preservation technology is used to protect the items from deterioration. Three different production levels are considered. It is assumed that initially the production rate is at a lower rate and it increases gradually over the period. This is just in order to reduce the holding cost by avoiding the larger stock quantity at the beginning of the production cycle. The shortages are permitted and fully backordered. The objective of the production inventory model is to determine the optimal production policy which minimizes the manufacturer's total cost. Theoretical results are established in order to demonstrate the existence of the optimal solution and a proper solution procedure is presented. A numerical example and sensitivity analysis are presented to validate the theoretical results. Also, some managerial insights are provided.
\end{abstract}

Mathematics Subject Classification. 90B05.

Received September 12, 2017. Accepted April 20, 2019.

\section{INTRODUCTION AND LITERATURE REVIEW}

\subsection{Motivation}

From the development of the economic order quantity and economic production quantity (EOQ/EPQ) inventory models, a lot of research works have been made in the inventory management field. In today's competitive world, every manufacturing organization wants to deliver the best product to customers because they have more concern about the quality of items that they are purchasing. This leads to manufacturers to invest more on improvement of the manufacturing process. As now, it is a world known fact that one cannot ignore the effect of deterioration of products. Therefore, in order to reduce the deterioration rate, the manufacturer can use some different kind of technologies such as refrigerating the items. This technology is known as preservation

Keywords. EPQ, preservation technology, shortages, controllable deterioration rate, three-level production rates.

1 Universidad de Monterrey, Av. Ignacio Morones Prieto 4500 Pte., 66238 San Pedro Garza García, Nuevo León, Mexico.

2 Faculty of Science \& Technology, ICFAI University, Tripura, Kamalghat, Sadar, West Tripura, Tripura 799210, India.

3 The Logistics Institute-Asia Pacific, National University of Singapore, 21 Heng Mui Keng Terrace, \#04-01, 119613, Singapore.

4 Department of Industrial and Systems Engineering, School of Engineering and Sciences, Tecnológico de Monterrey, E. Garza Sada 2501 Sur, Monterrey, 64849 Nuevo León, Mexico.

${ }^{*}$ Corresponding author: lecarden@itesm.mx; lecarden@hotmail.com 
technology. Many research works have been done considering the above said technology but very few consider a production inventory model for deteriorating items having three different production rates and preservation technology together. In most of the recent articles, it is considered that the production rate throughout the period is same which is not quite realistic. This motivated us to consider such a manufacturing system having different production rates over the cycle period. In this direction, this paper considers three different production levels, it is assumed that initially the production rate is at lower rate and it rises progressively over the production cycle. This is just with the aim to diminish the holding cost by evading the higher stock quantity initially. Furthermore, this production inventory model considers that shortages occur and these are fully backordered.

\subsection{Literature review}

The primary research areas relevant to this paper are underline here. In this subsection, it is discussed about the primary research done in the area of inventory models considering (1) deterioration, (2) economic production quantity (EPQ) inventory model and (3) preservation technology.

In past it was assumed that items preserve its original quality over the period of time. However, Ghare and Schrader [9] introduced the concept of deterioration and explained the importance of deterioration in inventory models. Later, Covert and Philip [6] developed an economic order quantity (EOQ) inventory model for deteriorating items whose time to deterioration follows a two-parameter Weibull distribution. After that, many researchers derived so many inventory models for deteriorating items considering different situations that can occur in real world. The most of the work done in inventory field considering deterioration is summarized in the following literature review papers written by Raafat [19], Goyal and Giri [10], Bakker et al. [1], and Janssen et al. [15].

Misra [18] built an EPQ inventory model. He obtained an approximate relation between the length of the production time and that of the nonproduction time in a cycle for a constant rate of deterioration. Until today there are lot of improved and efficient integrated inventory models that have developed by several researchers and academicians. Goyal and Gunasekaran [12] introduced an EPQ inventory model for a multi-stage production system. Balkhi and Benkherouf [3] formulated an EPQ inventory model for exponentially deteriorating items, in which the production rate and the demand rate are functions of time. Balkhi [2] extended Balkhi and Benkherouf [3]'s inventory model by considering deterioration rate as a function of time. Wee [24], Chang and Dye [5], Goyal and Giri [11], and Wu et al. [26] proposed EOQ and/or EPQ inventory models with partial backordering. Cárdenas-Barrón [4] presented the derivation of EOQ/EPQ inventory models with two backorders costs using analytic geometry and algebra. Sarkar and Moon [21] derived a production inventory model having imperfect quality items and inflation. Widyadana and Wee [25] developed an EPQ inventory model for exponentially deteriorating items with multiple production setups followed by one rework setup in each cycle.

As deterioration plays a vital role while making inventory control decision, so every organization wants to reduce the deterioration rate of products as much as possible. Therefore, preservation technology investment plays a significant role to control deterioration rate. In present day, preservation technology is drawing increasing attention from researchers and academicians. Hsu et al. [14] proposed an inventory model for a deteriorating item considering preservation technology to decrease deterioration rate. Lee and Dye [16] developed an inventory model having preservation technology investment, with allowable shortages and stock-dependent selling rate. Dye [7] studied the effect of preservation technology investment on inventory policy for a non-instantaneous deteriorating item. Hsieh and Dye [13] established an EPQ inventory model for deteriorating items under preservation technology with time-varying demand and finite replenishment rate. Zhang et al. [28] provided an effective algorithm for an inventory model considering pricing, preservation technology investment and inventory control for deterioration items. Liu et al. [17] developed the joint dynamic pricing and preservation technology investment inventory model. They assumed that the demand rate of items depends on price and quality. Furthermore, Zhang et al. [29] investigated a two-echelon supply chain model for deteriorating items where both manufacturer and retailer jointly invest in preservation technology to reduce deterioration rate. Researchers such as Dye and Hsieh [8], Yang et al. [27], Tsao et al. [22], Zhang et al. [30], and Saha et al. [20] studied inventory models with preservation technology investment for deteriorating items. 
In this work, a production inventory model for controllable deteriorating items in which three different levels of production are derived, and it is possible that production starts at one rate, after some time, it changes over to another rate and afterwards, it switches again to another rate. Such a situation is desirable in the sense that by starting at a low rate of production, a large quantum stock of manufactured item at the first stage is avoided and consequently leading to reduction in the holding cost.

The rest part of the paper is organized as follows. Section 2 describes the notation and assumptions that have been used in the development of the production inventory model for controllable deterioration rate with shortages. Then, Section 3 establishes the mathematical model of the production inventory model. Section 4 derives the theoretical results and with these proposes an algorithm to obtain the global optimal solution. Section 5 solves a numerical example and proves graphically that the total cost function is convex. Section 6 presents a sensitivity analysis. Finally, Section 7 provides some conclusions and future research directions.

\section{Notation AND ASSUmptions}

The production inventory model is developed with the following notation and assumptions.

\subsection{Notation}

This section defines the notation that is used in the production inventory model for controllable deterioration rate with shortages.

\begin{tabular}{ll}
\hline$p:$ & Production rate in units per unit time. \\
$d:$ & Demand rate in units per unit time. \\
$q_{1}:$ & On-hand inventory level at time $t_{1}$ in units. \\
$q_{2}:$ & On-hand inventory level at time $t_{2}$ in units. \\
$q_{3}:$ & On-hand inventory level at time $t_{3}$ in units. \\
$q:$ & Production quantity in units. \\
$c_{p}:$ & Production cost per unit. \\
$c_{h}:$ & Holding cost per unit per unit time. \\
$c_{s}:$ & Shortage cost per unit per unit time. \\
$c_{0}:$ & Setup cost per setup. \\
$t_{i}:$ & Time in period $i$ ( $i=1,2,3,4,5)$. \\
PC: & Production cost per unit time. \\
OC: & Setup cost per unit time. \\
HC: & Total holding cost per unit time. \\
DC: & Deteriorating cost per unit time. \\
PTC: & Preservation technology cost per unit time. \\
SC: & Shortage cost per unit time. \\
TC: & Total cost per unit time. \\
\hline
\end{tabular}

\subsection{Assumptions}

(i) The demand rate is known, constant, and continuous.

(ii) Items are produced and added to the inventory.

(iii) Three rates of production are considered as in Viji and Karthikeyan [23].

(iv) A single product is considered; the product does not interact with any other inventory items.

(v) The production rate is always greater than or equal to the sum of the demand rate and defective items.

(vi) The deterioration rate is assumed continuous, decreasing and convex function of capital investment in preservation technology $\zeta$, i.e. $\partial \lambda(\zeta) / \partial \zeta<0, \partial^{2} \lambda(\zeta) / \partial \zeta^{2}>0$. It is considered that $\lambda(\zeta)=\lambda_{0} \mathrm{e}^{-\eta \zeta}$, where " $\zeta$ " is a decision variable. Here, $\lambda(\zeta)$ is the deterioration rate after investing on preservation technology, 
$\lambda_{0}$ is the deterioration rate without preservation technology investment, and $\eta$ is a coefficient that represents the increasing in $\lambda(\zeta)$ per $\$ /$ unit/time.

(vii) The cost of preservation technology investment per unit time is restricted to $\zeta \in[0, \bar{\zeta}]$.

\section{MATHEMATiCAl Formulation of THE PRODUCTION INVENTORY MODEL FOR CONTROLLABLE DETERIORATION RATE WITH SHORTAGES}

This section develops the production inventory for controllable deterioration rate with shortages. The production inventory model for controllable deterioration rate with shortages is depicted in Figure 1 . The cycle starts at $t=0$ and the inventory accumulates at a rate of $p-d$. During the time $t_{1}$ the production rate is $p$ and the demand rate is $d$. During the time $t_{2}-t_{1}$ the production rate is " $a(>1)$ " times of $p$, i.e. ap and demand rate is also " $a(>1)$ " times of $d$, i.e. $a d$ where " $a(>1)$ " is a constant. Consequently, the inventory is accumulated at a rate of $a(p-d)$. During the time $t_{3}-t_{2}$ the production rate is " $b(b>a>1)$ " times of $p$, i.e. $b p$ and demand rate is also " $b(b>a>1)$ " times of $d$, i.e. $b d$ where " $b(b>a>1)$ " is a constant. Hence, the inventory is accumulated at a rate of $b(p-d)$. This kind of three production rates was used also by Viji and Karthikeyan [23]. During the whole time $t_{4}$, the product deteriorates. Therefore, a care must be taken to control the amount of stocks of the product. During time $t_{4}-t_{3}$ the maximum inventory level starts to decrease due to demand at a rate of $d$ and the inventory level is zero at time $t_{4}$. At time $t_{4}$ shortages start to accumulate at a rate $d$ up to time $t_{5}$. Thus, the time $t_{5}-t_{4}$ is needed to build up $S$ units of items. The production restarts again at time $t_{5}$ at a rate of $p-d$ to satisfy both the shortages of previous cycle and current demand during the time $t_{6}-t_{5}$. Time $t_{6}$ is required to consume all units $q$ at demand rate; where $q=d t_{6}$.

Let $q(t)$ denotes the inventory level at time $t$. The differential equations that describe the inventory behaviour in the interval $\left[0, t_{6}\right]$ are given below.

$$
\begin{array}{ll}
\frac{\mathrm{d} q(t)}{\mathrm{d} t}+\lambda(\zeta) q(t)=(p-d), & 0 \leq t \leq t_{1} \\
\frac{\mathrm{d} q(t)}{\mathrm{d} t}+\lambda(\zeta) q(t)=a(p-d), & t_{1} \leq t \leq t_{2} \\
\frac{\mathrm{d} q(t)}{\mathrm{d} t}+\lambda(\zeta) q(t)=b(p-d), & t_{2} \leq t \leq t_{3} \\
\frac{\mathrm{d} q(t)}{\mathrm{d} t}+\lambda(\zeta) q(t)=-d, & t_{3} \leq t \leq t_{4} \\
\frac{\mathrm{d} q(t)}{\mathrm{d} t}=-d, & t_{4} \leq t \leq t_{5} \\
\frac{\mathrm{d} q(t)}{\mathrm{d} t}=(p-d), & t_{5} \leq t \leq t_{6} .
\end{array}
$$

The boundary conditions are $q(0)=0, q\left(t_{1}\right)=q_{1}, q\left(t_{2}\right)=q_{2}, q\left(t_{3}\right)=q_{3}, q\left(t_{4}\right)=0, q\left(t_{5}\right)=-S$ and $q\left(t_{6}\right)=0$. Solving the equations (3.1)-(3.6) yields,

$$
\begin{array}{rlrl}
q(t) & =\frac{(p-d)}{\lambda(\zeta)}\left[1-\mathrm{e}^{-\lambda(\zeta) t}\right], & & \leq t \leq t_{1} \\
q(t) & =\frac{a(p-d)}{\lambda(\zeta)}\left[1-\mathrm{e}^{-\lambda(\zeta) t}\right], & t_{1} \leq t \leq t_{2} \\
q(t)=\frac{b(p-d)}{\lambda(\zeta)}\left[1-\mathrm{e}^{-\lambda(\zeta) t}\right], & t_{2} \leq t \leq t_{3} \\
q(t)=\frac{d}{\lambda(\zeta)}\left[\mathrm{e}^{\lambda(\zeta)\left(t_{4}-t\right)}-1\right], & t_{3} \leq t \leq t_{4} \\
q(t)=-d\left[t_{4}-t\right], & t_{4} \leq t \leq t_{5},
\end{array}
$$




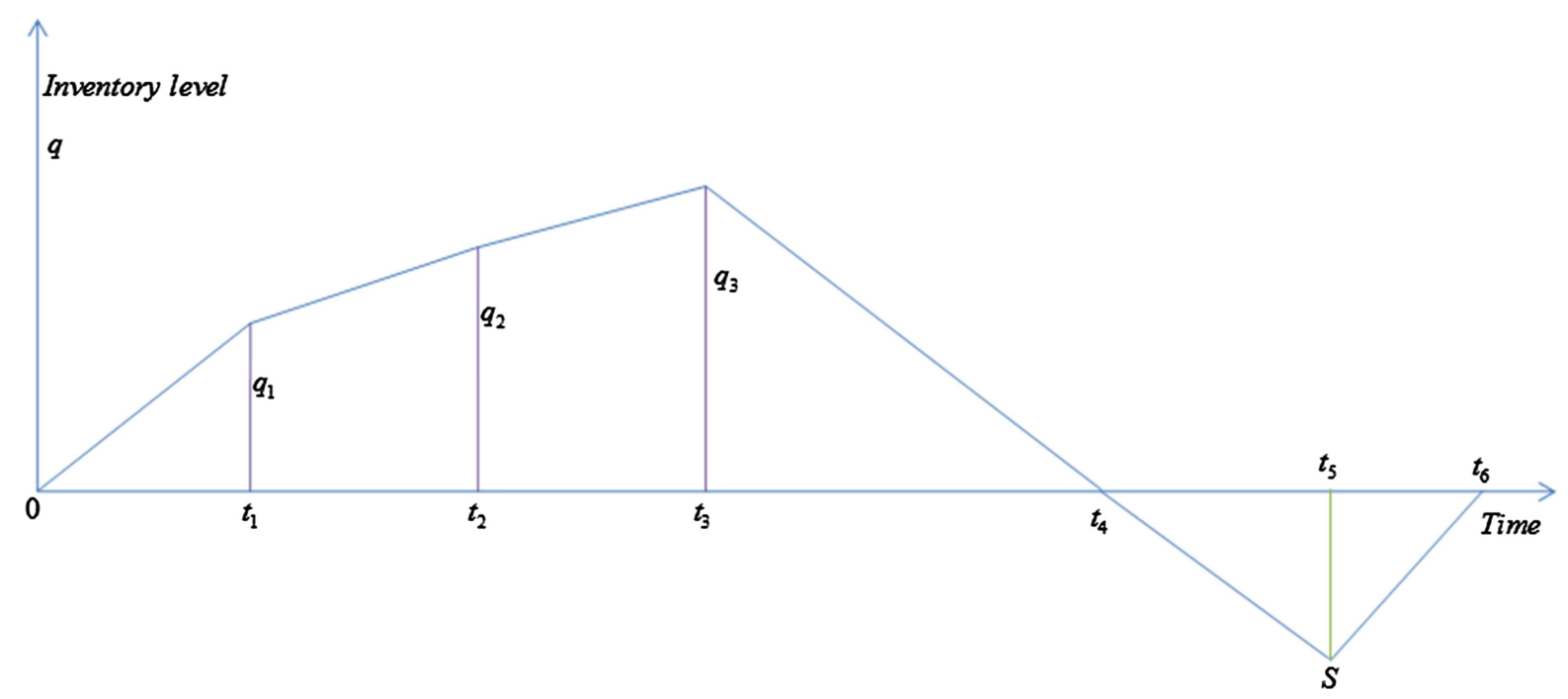

FiguRE 1. The production inventory model for controllable deterioration rate with shortages.

and

$q(t)=(p-d)\left[t_{6}-t\right], \quad t_{5} \leq t \leq t_{6}$

The maximum inventory during time $t_{1}$ is $q\left(t_{1}\right)=q_{1} \Rightarrow q_{1}=\frac{(p-d)}{\lambda(\zeta)}\left[1-\mathrm{e}^{-\lambda(\zeta) t_{1}}\right]$

The maximum inventory during time $t_{2}$ is $q\left(t_{2}\right)=q_{2} \Rightarrow q_{2}=\frac{a(p-d)}{\lambda(\zeta)}\left[1-\mathrm{e}^{-\lambda(\zeta) t_{2}}\right]$

The maximum inventory during time $t_{3}$ is $q\left(t_{3}\right)=q_{3} \Rightarrow q_{3}=\frac{b(p-d)}{\lambda(\zeta)}\left[1-\mathrm{e}^{-\lambda(\zeta) t_{3}}\right]$.

Using the boundary condition in equation (3.11), then shortage level $S$ is

$$
q\left(t_{5}\right)=-S \Rightarrow d\left(t_{5}-t_{4}\right)=-S .
$$

Using the boundary condition in equation (3.12),

$$
\begin{aligned}
q\left(t_{5}\right) & =-S \Rightarrow(p-d)\left(t_{6}-t_{5}\right)=-S . \\
\text { So, } d\left(t_{5}-t_{4}\right) & =(p-d)\left(t_{6}-t_{5}\right) \Rightarrow t_{5}=\frac{d t_{4}}{p}+\frac{(p-d) t_{6}}{p} .
\end{aligned}
$$

Next, the total cost of the inventory system is computed using the following cost terms:

(i) Production cost per unit time:

$$
\mathrm{PC}=d c_{p}
$$

(ii) Setup cost per unit time:

$$
\mathrm{OC}=\frac{c_{0}}{t_{6}}
$$

(iii) Holding cost per unit time: 


$$
\begin{aligned}
& \mathrm{HC}=\frac{c_{h}}{t_{6}}\left[\int_{0}^{t_{1}} q(t) \mathrm{d} t+\int_{t_{1}}^{t_{2}} q(t) \mathrm{d} t+\int_{t_{2}}^{t_{3}} q(t) \mathrm{d} t+\int_{t_{3}}^{t_{4}} q(t) \mathrm{d} t\right] \\
& \mathrm{HC}=\frac{c_{h}}{t_{6}}\left\{\begin{array}{l}
\int_{0}^{t_{1}} \frac{(p-d)}{\lambda(\zeta)}\left[1-\mathrm{e}^{-\lambda(\zeta) t}\right] \mathrm{d} t+\int_{t_{1}}^{t_{2}} \frac{a(p-d)}{\lambda(\zeta)}\left[1-\mathrm{e}^{-\lambda(\zeta) t}\right] \mathrm{d} t \\
+\int_{t_{2}}^{t_{3}} \frac{b(p-d)}{\lambda(\zeta)}\left[1-\mathrm{e}^{-\lambda(\zeta) t}\right] \mathrm{d} t+\int_{t_{3}}^{t_{4}} \frac{d}{\lambda(\zeta)}\left[\mathrm{e}^{\lambda(\zeta)\left(t_{4}-t\right)}-1\right] \mathrm{d} t
\end{array}\right\} \\
& \mathrm{HC}=\frac{c_{h}}{t_{6}}\left[\frac{(p-d)}{\{\lambda(\zeta)\}^{2}}\left\{\lambda(\zeta) t_{1}+\mathrm{e}^{-\lambda(\zeta) t_{1}}-1\right\}+\frac{a(p-d)}{\{\lambda(\zeta)\}^{2}}\left\{\lambda(\zeta)\left(t_{2}-t_{1}\right)+\mathrm{e}^{-\lambda(\zeta) t_{2}}-\mathrm{e}^{-\lambda(\zeta) t_{1}}\right\}\right. \\
& \left.+\frac{b(p-d)}{\{\lambda(\zeta)\}^{2}}\left\{\lambda(\zeta)\left(t_{3}-t_{2}\right)+\mathrm{e}^{-\lambda(\zeta) t_{3}}-\mathrm{e}^{-\lambda(\zeta) t_{2}}\right\}-\frac{d}{\{\lambda(\zeta)\}^{2}}\left\{1-\mathrm{e}^{\lambda(\zeta)\left(t_{4}-t_{3}\right)}+\lambda(\zeta)\left(t_{4}-t_{3}\right)\right\}\right]
\end{aligned}
$$

(iv) Deteriorating cost per unit time:

$$
\begin{aligned}
\mathrm{DC}= & \frac{\lambda(\zeta) c_{p}}{t_{6}}\left[\int_{0}^{t_{1}} q(t) \mathrm{d} t+\int_{t_{1}}^{t_{2}} q(t) \mathrm{d} t+\int_{t_{2}}^{t_{3}} q(t) \mathrm{d} t+\int_{t_{3}}^{t_{4}} q(t) \mathrm{d} t\right] \\
\mathrm{DC}= & \frac{\lambda(\zeta) c_{p}}{t_{6}}\left[\int_{0}^{t_{1}} \frac{(p-d)}{\lambda(\zeta)}\left[1-\mathrm{e}^{-\lambda(\zeta) t}\right] \mathrm{d} t+\int_{t_{1}}^{t_{2}} \frac{a(p-d)}{\lambda(\zeta)}\left[1-\mathrm{e}^{-\lambda(\zeta) t}\right] \mathrm{d} t\right. \\
& \left.+\int_{t_{2}}^{t_{3}} \frac{b(p-d)}{\lambda(\zeta)}\left[1-\mathrm{e}^{-\lambda(\zeta) t}\right] \mathrm{d} t+\int_{t_{3}}^{t_{4}} \frac{d}{\lambda(\zeta)}\left[\mathrm{e}^{\lambda(\zeta)\left(t_{4}-t\right)}-1\right] \mathrm{d} t\right] \\
\mathrm{DC}= & \frac{\lambda(\zeta) c_{p}}{t_{6}}\left[\frac{(p-d)}{\{\lambda(\zeta)\}^{2}}\left\{\lambda(\zeta) t_{1}+\mathrm{e}^{-\lambda(\zeta) t_{1}}-1\right\}+\frac{a(p-d)}{\{\lambda(\zeta)\}^{2}}\left\{\lambda(\zeta)\left(t_{2}-t_{1}\right)+\mathrm{e}^{-\lambda(\zeta) t_{2}}-\mathrm{e}^{-\lambda(\zeta) t_{1}}\right\}\right. \\
& \left.+\frac{b(p-d)}{\{\lambda(\zeta)\}^{2}}\left\{\lambda(\zeta)\left(t_{3}-t_{2}\right)+\mathrm{e}^{-\lambda(\zeta) t_{3}}-\mathrm{e}^{-\lambda(\zeta) t_{2}}\right\}-\frac{d}{\{\lambda(\zeta)\}^{2}}\left\{1-\mathrm{e}^{\lambda(\zeta)\left(t_{4}-t_{3}\right)}+\lambda(\zeta)\left(t_{4}-t_{3}\right)\right\}\right](3.2
\end{aligned}
$$

(v) Shortage cost per unit time:

$$
\begin{aligned}
& \mathrm{SC}=\frac{c_{s}}{t_{6}}\left[\int_{t_{4}}^{t_{5}} q(t) \mathrm{d} t+\int_{t_{5}}^{t_{6}} q(t) \mathrm{d} t\right] \\
& \mathrm{SC}=\frac{c_{s}}{t_{6}}\left[\int_{t_{4}}^{t_{5}} d\left[t-t_{4}\right] \mathrm{d} t+\int_{t_{5}}^{t_{6}}(p-d)\left[t_{6}-t\right] \mathrm{d} t\right] \\
& \mathrm{SC}=\frac{d c_{s}(p-d)}{p t_{6}}\left[t_{6}-t_{4}\right]^{2} .
\end{aligned}
$$

(vi) Preservation technology cost per unit time:

$$
\mathrm{PTC}=\frac{\zeta t_{6}}{t_{6}} .
$$

Hence, the total cost is: $\mathrm{TC}=\mathrm{PC}+\mathrm{OC}+\mathrm{HC}+\mathrm{DC}+\mathrm{SC}+\mathrm{PTC}$

$$
\begin{aligned}
& \mathrm{TC}=d c_{p}+\frac{c_{0}}{t_{6}}+\frac{\left(c_{h}+\lambda(\zeta) c_{p}\right)}{t_{6}}\left[\frac{(p-d)}{\{\lambda(\zeta)\}^{2}}\left\{\lambda(\zeta) t_{1}+\mathrm{e}^{-\lambda(\zeta) t_{1}}-1\right\}+\frac{a(p-d)}{\{\lambda(\zeta)\}^{2}}\left\{\begin{array}{l}
\lambda(\zeta)\left(t_{2}-t_{1}\right) \\
+\mathrm{e}^{-\lambda(\zeta) t_{2}}-\mathrm{e}^{-\lambda(\zeta) t_{1}}
\end{array}\right\}\right. \\
& \left.+\frac{b(p-d)}{\{\lambda(\zeta)\}^{2}}\left\{\lambda(\zeta)\left(t_{3}-t_{2}\right)+\mathrm{e}^{-\lambda(\zeta) t_{3}}-\mathrm{e}^{-\lambda(\zeta) t_{2}}\right\}-\frac{d}{\{\lambda(\zeta)\}^{2}}\left\{1-\mathrm{e}^{\lambda(\zeta)\left(t_{4}-t_{3}\right)}+\lambda(\zeta)\left(t_{4}-t_{3}\right)\right\}\right] \\
& +\frac{d c_{s}(p-d)}{p t_{6}}\left[t_{6}-t_{4}\right]^{2}+\frac{\zeta t_{6}}{t_{6}} \text {. }
\end{aligned}
$$

\section{The THEORETiCAL RESUlts AND OPtimal SOLUtion}

This section derives the theoretical results and with these develops an algorithm to determine the optimal solution. 


\subsection{Theoretical results}

Proposition 4.1. If preservation technology $\operatorname{cost} \zeta \in[0, \bar{\zeta}]$ then the total cost TC is convex in time $t_{1}, t_{2}, t_{3}$, $t_{4}$ and $t_{6}$.

Proof. See Appendix A

Proposition 4.2. For known $t_{1}, t_{2}, t_{3}, t_{4}$ and $t_{6}$, the following is established:

(1) If $\Delta_{3}\left(t_{1}, t_{2}, t_{3}, t_{4}, t_{6}\right) \leq 0$ then $\mathrm{TC}\left(t_{1}, t_{2}, t_{3}, t_{4}, t_{6}, \zeta\right)$ has maximum value at $\zeta^{*}=0$.

(2) If $\Delta_{4}\left(t_{1}, t_{2}, t_{3}, t_{4}, t_{6}\right) \geq 0$ then $\mathrm{TC}\left(t_{1}, t_{2}, t_{3}, t_{4}, t_{6}, \zeta\right)$ has minimum value at $\zeta=\bar{\zeta}$.

(3) If $\Delta_{3}\left(t_{1}, t_{2}, t_{3}, t_{4}, t_{6}\right)>0$ and $\Delta_{4}\left(t_{1}, t_{2}, t_{3}, t_{4}, t_{6}\right)<0$ then $\mathrm{TC}\left(t_{1}, t_{2}, t_{3}, t_{4}, t_{6}, \zeta\right)$ is convex and reaches its global minimum at point $\zeta^{*} \in(0, \bar{\zeta})$, and it can be obtained setting $\frac{\partial\left(\mathrm{TC}\left(t_{1}, t_{2}, t_{3}, t_{4}, t_{6}, \zeta\right)\right)}{\partial \zeta}=0$.

Proof. See Appendix B

Combining Propositions 4.1 and 4.2 then Proposition 4.3 is stated.

Proposition 4.3. The optimal solution $\left(t_{1}^{*}, t_{2}^{*}, t_{3}^{*}, t_{4}^{*}, t_{6}^{*}, \zeta^{*}\right)$ that minimizes the total $\operatorname{cost} \operatorname{TC}\left(t_{1}, t_{2}, t_{3}, t_{4}, t_{6}, \zeta\right)$ exists and is unique.

Moreover, the convexity of the total cost $\mathrm{TC}\left(t_{1}, t_{2}, t_{3}, t_{4}, t_{6}, \zeta\right)$ is proved numerically and graphically (see Section 5).

\subsection{Algorithm for finding the optimal solution}

Based on the mathematical results presented in Section 4.1, the following iterative algorithm is proposed.

Algorithm

Step 1. Set $i=0$, initialize the value of $\zeta_{i}$ and establish the calculation accuracy equal to $10^{-4}$.

Step 2. Determine the initial solution of $t_{1}, t_{2}, t_{3}, t_{4}$, and $t_{6}$ from equation (A.6) when

$$
\zeta_{i} \in[0, \bar{\zeta}] .
$$

Step 3. Calculate $\Delta_{3}\left(t_{1}, t_{2}, t_{3}, t_{4}, t_{6}\right), \Delta_{4}\left(t_{1}, t_{2}, t_{3}, t_{4}, t_{6}\right)$ and execute one of following three cases:

(1) If $\Delta_{3}\left(t_{1}, t_{2}, t_{3}, t_{4}, t_{6}\right) \leq 0$ then $\zeta_{i}=0$.

(2) If $\Delta_{4}\left(t_{1}, t_{2}, t_{3}, t_{4}, t_{6}\right) \geq 0$ then $\zeta_{i}=\bar{\zeta}$.

(3) If $\Delta_{3}\left(t_{1}, t_{2}, t_{3}, t_{4}, t_{6}\right)>0$ and $\Delta_{4}\left(t_{1}, t_{2}, t_{3}, t_{4}, t_{6}\right)<0$, obtain the value of $\zeta_{i+1}$ by solving equation (B.3).

Step 4. If $\left|\zeta_{i+1}-\zeta_{i}\right| \leq 10^{-4}$ then set $\zeta^{*}=\zeta_{i+1}$ therefore the $\left(t_{1}^{*}, t_{2}^{*}, t_{3}^{*}, t_{4}^{*}, t_{6}^{*}, \zeta^{*}\right)$ is the optimal solution and go to Step 5. Otherwise, set $i=i+1$ and go to Step 2 .

Step 5. Calculate $\mathrm{TC}\left(t_{1}^{*}, t_{2}^{*}, t_{3}^{*}, t_{4}^{*}, t_{6}^{*}, \zeta^{*}\right)$ from equation (3.23).

Step 6. Calculate $t_{5}^{*}, q_{1}^{*}, q_{2}^{*}, q_{3}^{*}, q^{*}, S^{*}$ and report the optimal solution.

Step 7. Stop.

\subsection{A special case: The production inventory model for controllable deterioration rate without shortages}

It is worth mentioning that if $c_{s} \rightarrow \infty$ (i.e. no shortage), then the proposed inventory model reduces to without shortages case and equation (3.23) reduces to:

$$
\begin{aligned}
\mathrm{TC} & =d c_{p}+\frac{c_{0}}{t_{6}}+\frac{\left(c_{h}+\lambda(\zeta) c_{p}\right)}{t_{6}}\left[\frac{(p-d)}{\{\lambda(\zeta)\}^{2}}\left\{\lambda(\zeta) t_{1}+\mathrm{e}^{-\lambda(\zeta) t_{1}}-1\right\}+\frac{a(p-d)}{\{\lambda(\zeta)\}^{2}}\left\{\begin{array}{l}
\lambda(\zeta)\left(t_{2}-t_{1}\right) \\
+\mathrm{e}^{-\lambda(\zeta) t_{2}}-\mathrm{e}^{-\lambda(\zeta) t_{1}}
\end{array}\right\}\right. \\
& \left.+\frac{b(p-d)}{\{\lambda(\zeta)\}^{2}}\left\{\lambda(\zeta)\left(t_{3}-t_{2}\right)+\mathrm{e}^{-\lambda(\zeta) t_{3}}-\mathrm{e}^{-\lambda(\zeta) t_{2}}\right\}-\frac{d}{\{\lambda(\zeta)\}^{2}}\left\{1-\mathrm{e}^{\lambda(\zeta)\left(t_{4}-t_{3}\right)}+\lambda(\zeta)\left(t_{4}-t_{3}\right)\right\}\right]+\frac{\zeta t_{6}}{t_{6}} .
\end{aligned}
$$




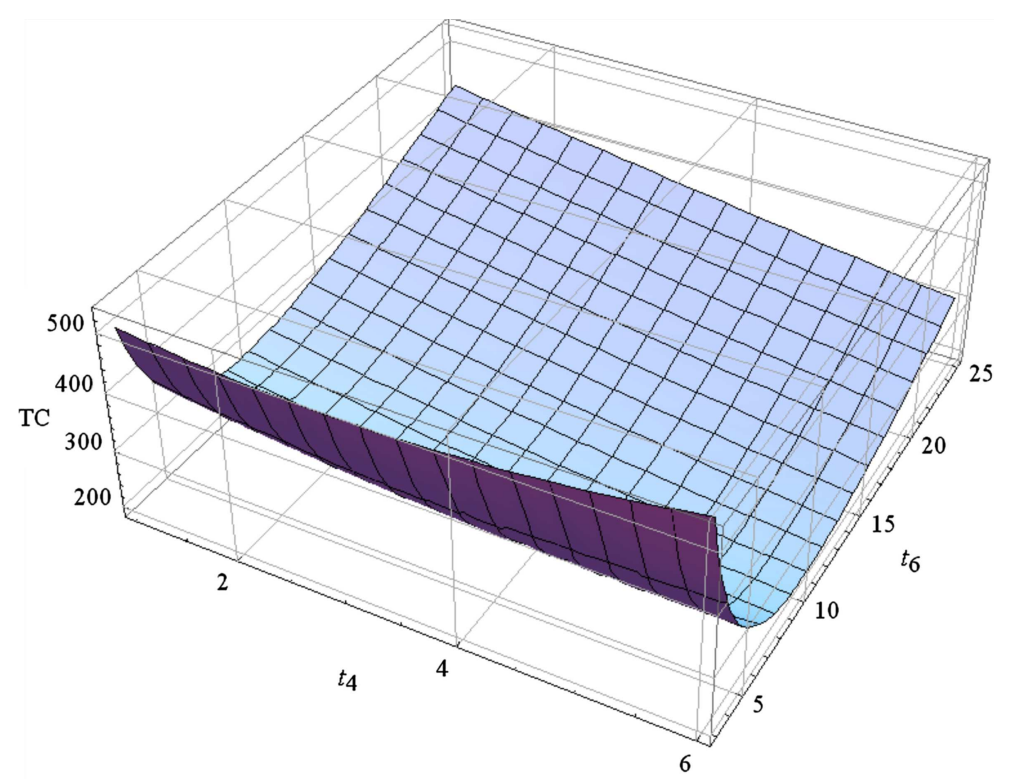

Figure 2. Convexity of TC with respect to $t_{4}$ and $t_{6}$.

\section{Numerical EXAMPLE}

This section presents a numerical example that illustrates the application of the production inventory model for controllable deterioration rate with shortages.

Example. Let $c_{0}=\$ 700$ per setup, $p=400$ units/week $d=20$ units/week, $a=2, b=2.5, c_{h}=\$ 0.2 /$ unit/week, $c_{p}=\$ 0.8 /$ unit, $c_{s}=\$ 0.8 /$ unit $/$ week, $\lambda_{0}=0.2$ unit, $\bar{\zeta}=14$ and $\eta=0.7$. By applying the algorithm, the following optimal solution is determined: $t_{1}^{*}=0.237589$ weeks, $t_{2}^{*}=0.263965$ weeks, $t_{3}^{*}=2.63737$ weeks, $t_{4}^{*}=3.51353$ weeks, $t_{5}^{*}=3.62312$ weeks, $t_{6}^{*}=3.62889$ weeks, $\zeta^{*}=\$ 12.5585, q_{1}^{*}=90.2835$ units, $q_{2}^{*}=$ 200.613 units, $q_{3}^{*}=2505.4$ units, $q^{*}=72.5778$ units, $S^{*}=2.1918$ units, $\mathrm{TC}^{*}=\$ 403.088, \frac{\partial^{2} \mathrm{TC}}{\partial t_{1}^{2}}=62.8363>$ $0 \frac{\partial^{2} \mathrm{TC}}{\partial t_{2}^{2}}=94.2544>0, \frac{\partial^{2} T C}{\partial t_{3}^{2}}=53.4622>0, \frac{\partial^{2} \mathrm{TC}}{\partial t_{4}^{2}}=9.47965>0, \frac{\partial^{2} \mathrm{TC}}{\partial t_{6}^{2}}=64.7257>0, \quad \frac{\partial^{2} \mathrm{TC}}{\partial \zeta^{2}}=0.0086353>$ $0, \Delta_{3}\left(t_{1}, t_{2}, t_{3}, t_{4}, t_{6}\right)=-53.7513<0$ and $\Delta_{3}\left(t_{1}, t_{2}, t_{3}, t_{4}, t_{6}\right)=0.995584>0$.

Notice that it can be shown graphically that the total cost function TC is a convex function and this demonstrates that the solution is a global optimal solution. If the total cost function (23) is plotted with some values of $t_{4}$ and $t_{6}$ such that $t_{4}$ is $1-6$ and $t_{6}$ is 3-25 then it is obtained a strictly convex graph of total cost function TC given by the Figure 2. From Figure 2, it can be observed that the optimal solution for $t_{4}$ and $t_{6}$ exists and the total cost of the inventory system is a convex function. Additionally, the convexity of the total cost function TC is shown in Figure 3 with respect to $t_{4}$ and $\zeta$ such that $t_{4}$ is $1-6$ and $\zeta$ is $0-14$ then a strictly convex graph of the total cost function TC is obtained. From Figure 3, it can be noted that the optimal solution for $t_{4}$ and $\zeta$ exists and the total cost of the inventory system is a convex function. Furthermore, the convexity of the total cost function TC is shown in Figure 4 with respect to $t_{6}$ and $\zeta$ such that $t_{6}$ is $3-25$ and $\zeta$ is $0-14$ then a strictly convex graph of total cost function TC is observed. The convexity of the total cost function TC is shown in Figure 5 with respect to $t_{4}$ considering fixed values for $t_{6}=3.62889$ and $\zeta=12.5585$. The convexity of the total cost function TC is shown in Figure 6 with respect to $t_{6}$ taking into consideration fixed values for $t_{4}=3.51353$ and $\zeta=12.5585$. The convexity of the total cost function $T C$ is shown in Figure 7 with respect to $\zeta$ taking into account fixed values for $t_{4}=3.51353$ and $t_{6}=3.62889$. Then, according to Figures $2-7$, it is verified that that the total cost TC is strictly a convex function. 


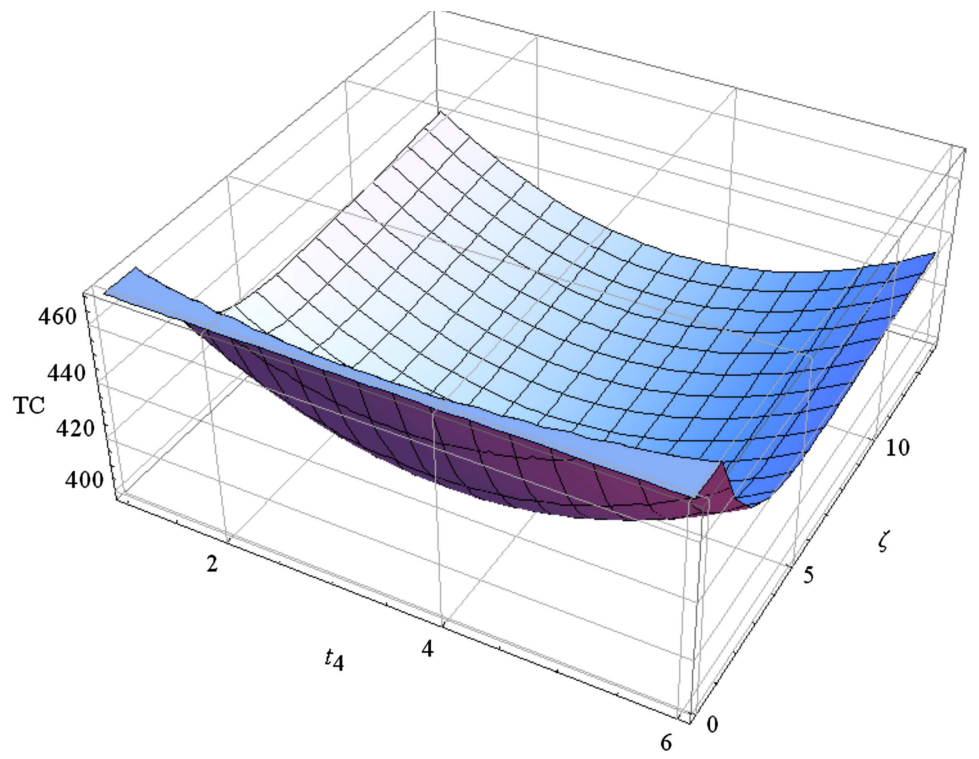

Figure 3. Convexity of TC with respect to $t_{4}$ and $\zeta$.

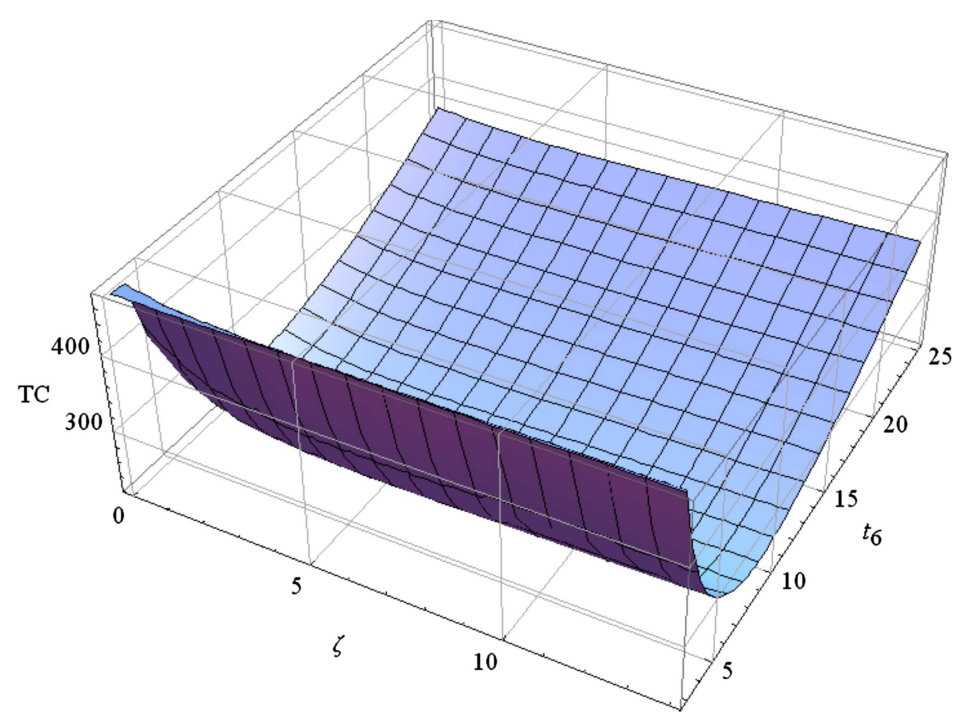

Figure 4. Convexity of TC with respect to $t_{6}$ and $\zeta$.

\section{SENSITIVE ANALYSIS}

This section presents a sensitivity analysis, which studies the effects of changes in the parameters $c_{0}, p, d, a, b, c_{h}, c_{p}, c_{s}, \lambda_{0}$ and $\eta$ by modifying each parameter, considering one parameter at a time, and leaving the rest of parameters unchanged. Table 1 presents the sensitive analysis results with respect to the numerical example.

Based on the results of Table 1, the following observations are made. 


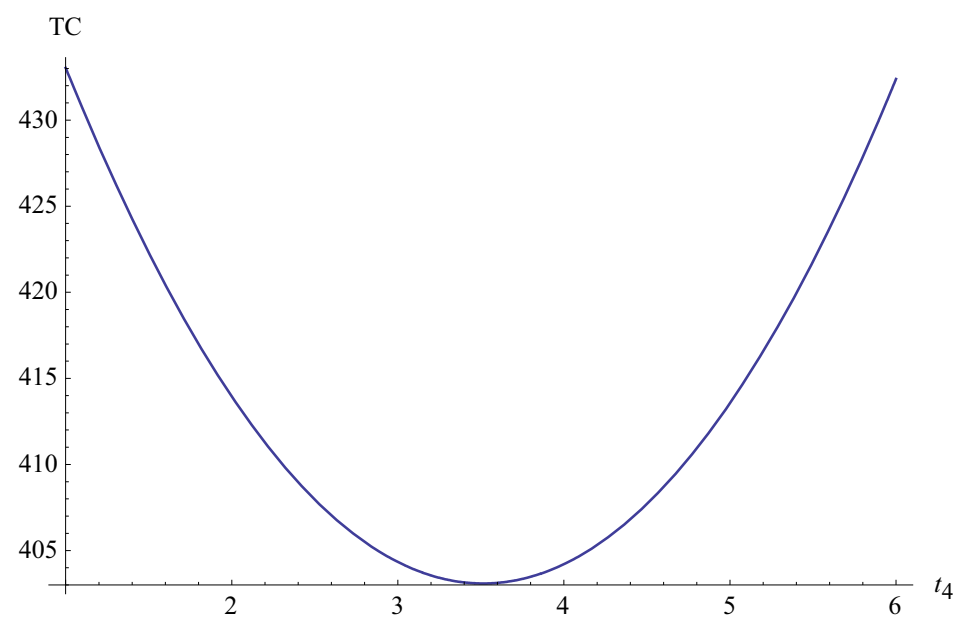

Figure 5. Convexity of TC with respect to $t_{4}$.

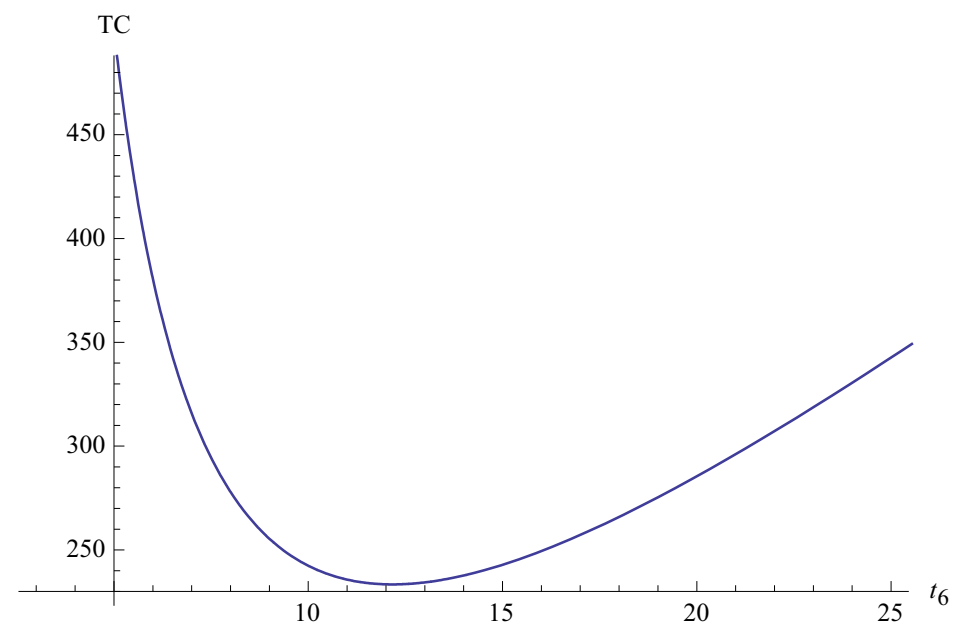

Figure 6. Convexity of TC with respect to $t_{6}$.

- With the increase in the value of setup cost $\left(c_{0}\right)$; the production lot size $\left(q^{*}\right)$, the maximum inventory $\left(q_{1}^{*}\right.$, $q_{2}^{*}$ and $\left.q_{3}^{*}\right)$, production time $\left(t_{1}, t_{2}, t_{3}\right)$, time $\left(t_{4}\right.$ and $\left.t_{5}\right)$, cycle time $\left(t_{6}\right)$ and total cost (TC) increase but preservation cost $(\zeta)$ decreases and shortage level $\left(S^{*}\right)$ does not change.

- With the increase of production rate $(p)$ then production lot size $\left(q^{*}\right)$, maximum inventory $\left(q_{1}^{*}, q_{2}^{*}\right.$ and $\left.q_{3}^{*}\right)$, production time $\left(t_{1}, t_{2}, t_{3}\right)$, time $\left(t_{4}\right.$ and $\left.t_{5}\right)$, cycle time $\left(t_{6}\right)$, shortage level $\left(S^{*}\right)$ and total cost (TC) decrease but preservation cost $(\zeta)$ increases. The preservation cost $(\zeta)$ increased because the manufacturing company invests more funds into the improvement of preservation technology to reduce the item's deterioration.

- When the value of demand rate $(d)$ increases, it can be observed that the production lot size $\left(q^{*}\right)$, maximum inventory $\left(q_{1}^{*}, q_{2}^{*}\right.$ and $\left.q_{3}^{*}\right)$, production time $\left(t_{1}, t_{2}, t_{3}\right)$, time $\left(t_{4}\right.$ and $\left.t_{5}\right)$, cycle time $\left(t_{6}\right)$, shortage level $\left(S^{*}\right)$ and total cost (TC) increase but preservation cost $(\zeta)$ decreases. This implies that when the market demand rate increases, it in turn makes the manufacturing company increases the production lot size $\left(q^{*}\right)$. 


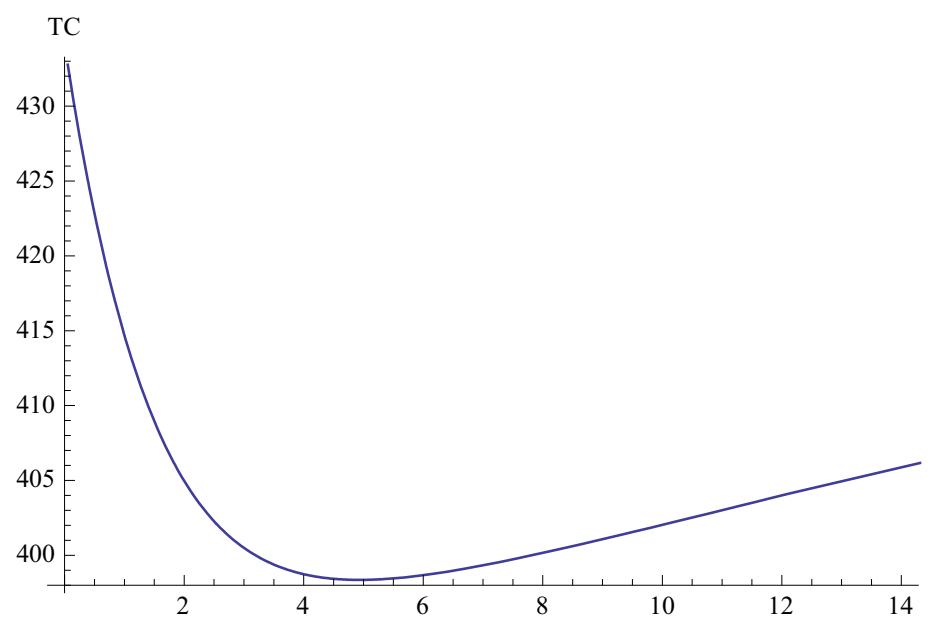

Figure 7. Convexity of TC with respect to $\zeta$.

- With the increase in rate of $a$ times of production $p$ and demand rate $d$, production lot size $\left(q^{*}\right)$, maximum inventory $\left(q_{1}^{*}, q_{2}^{*}\right.$ and $\left.q_{3}^{*}\right)$, production time $\left(t_{1}, t_{2}, t_{3}\right)$, time $\left(t_{4}\right.$ and $\left.t_{5}\right)$, and cycle time $\left(t_{6}\right)$, preservation cost $(\zeta)$ and total cost (TC) decrease but shortage level $\left(S^{*}\right)$ does not change.

- With the increase in rate of $b$ times of production $p$ and demand rate $d$, production lot size $\left(q^{*}\right)$, maximum inventory $\left(q_{1}^{*}, q_{2}^{*}\right.$ and $\left.q_{3}^{*}\right)$, production time $\left(t_{1}, t_{2}, t_{3}\right)$, time $\left(t_{4}\right.$ and $\left.t_{5}\right)$, cycle time $\left(t_{6}\right)$, shortage level $\left(S^{*}\right)$ and total cost (TC) decrease but preservation cost $(\zeta)$ increases, and shortage level $\left(S^{*}\right)$ does not change.

- With an increase in holding cost $\left(c_{h}\right)$ then the production lot size $\left(q^{*}\right)$, maximum inventory $\left(q_{1}^{*}, q_{2}^{*}\right.$ and $\left.q_{3}^{*}\right)$, production time $\left(t_{1}, t_{2}, t_{3}\right)$, time $\left(t_{4}\right.$ and $\left.t_{5}\right)$, cycle time $\left(t_{6}\right)$, preservation cost $(\zeta)$ and total cost $(\mathrm{TC})$ decrease but shortage level $\left(S^{*}\right)$ and preservation cost $(\zeta)$ increase. This result reveals that while facing a higher holding cost, the manufacturing company tends to reduce the length of replenishment cycle and produce a smaller lot size each time for keeping the firm's inventory level as low as possible. From this sense, in order to enhance the competitiveness, the manufacturing company must pay more attention to storage process control to reduce the holding cost.

- With an increase in production cost $\left(c_{p}\right)$ then the production lot size $\left(q^{*}\right)$, maximum inventory $\left(q_{1}^{*}, q_{2}^{*}\right.$ and $\left.q_{3}^{*}\right)$, production time $\left(t_{1}, t_{2}, t_{3}\right)$, time $\left(t_{4}\right.$ and $\left.t_{5}\right)$, cycle time $\left(t_{6}\right)$ increase but preservation cost $(\zeta)$, shortage level $\left(S^{*}\right)$ and total cost (TC) decrease.

- If shortage cost $\left(c_{s}\right)$ increases then the production lot size $\left(q^{*}\right)$, maximum inventory $\left(q_{1}^{*}, q_{2}^{*}\right.$ and $\left.q_{3}^{*}\right)$, production time $\left(t_{1}, t_{2}, t_{3}\right)$, time $\left(t_{4}\right.$ and $\left.t_{5}\right)$, cycle time $\left(t_{6}\right)$ and total cost (TC) increase but preservation cost $(\zeta)$ and shortage level $\left(S^{*}\right)$ decrease.

- With an increase in deterioration rate $\lambda_{0}$, the production lot size $\left(q^{*}\right)$, maximum inventory $\left(q_{1}^{*}, q_{2}^{*}\right.$ and $\left.q_{3}^{*}\right)$, production time $\left(t_{1}, t_{2}, t_{3}\right)$, time $\left(t_{4}\right.$ and $\left.t_{5}\right)$, cycle time $\left(t_{6}\right)$ and total cost (TC) decrease but preservation cost $(\zeta)$ and shortage level $\left(S^{*}\right)$ increase. This is due to the increment of the deteriorated quantity, so manufacturing company has to invest more on the preservation technology in order to decrease the deterioration.

- With the increase in coefficient $\eta$, the production lot size $\left(q^{*}\right)$, maximum inventory $\left(q_{1}^{*}, q_{2}^{*}\right.$ and $\left.q_{3}^{*}\right)$, production time $\left(t_{1}, t_{2}, t_{3}\right)$, time $\left(t_{4}\right.$ and $\left.t_{5}\right)$ and cycle time $\left(t_{6}\right)$ increase but preservation cost $(\zeta)$, shortage level $\left(S^{*}\right)$ and total cost (TC) decrease. Notice that when $\eta$ increases it is reduced the deterioration rate $\lambda(\zeta)$ because it is a decreasing function and that is why total cost (TC) decreases. As $\zeta$ increases then the total cost (TC) also decreases. Since there is less deterioration rate, more sales and more profit will be done. 


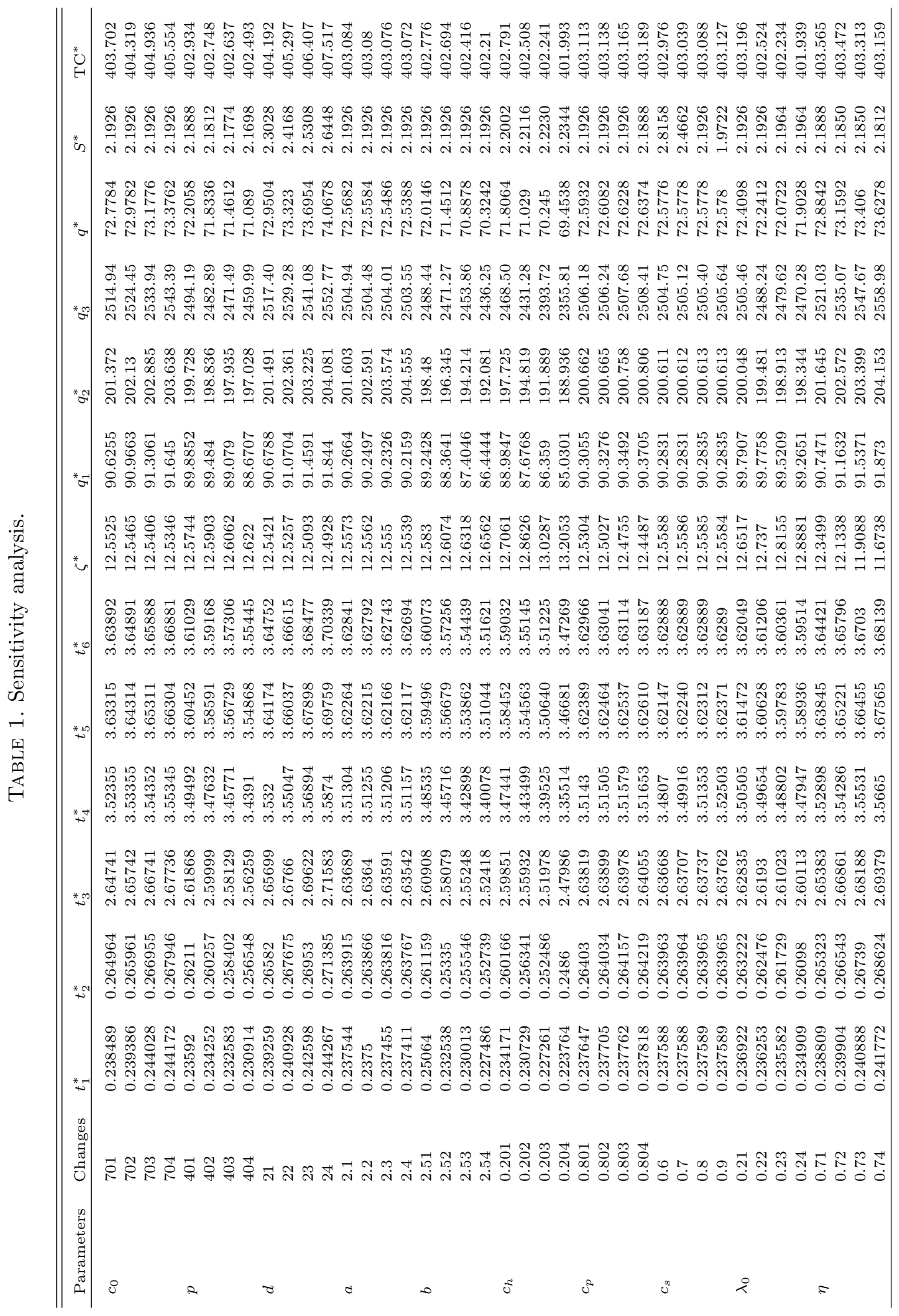




\section{Conclusion}

This paper deals with an inventory production system that has different types of production rates over the production cycle, where the manufacturer invests money on the implementation of preservation technologies to control the deterioration of manufactured products. Specifically, the inventory model considers three different production rates, it is considered that initially the production rate is at lower rate and it increases gradually over the production period. This is just in order to decrease the holding cost by avoiding the larger stock quantity initially. The shortages are permitted and fully backordered. The proposed inventory model can be very useful/handful for manufacturing companies that fabricate items that are deteriorating in nature; for example food and beverage companies. Theoretical results are derived in order to prove that the optimal solution for the given problem not only exists but it is also unique.

For the future research, one can extend this inventory model by considering integrated/joint inventory model for both manufacturer's and retailer's perspectives. One can also incorporate imperfect production systems. Additionally, it would be interesting to consider the effect of carbon emissions at manufacturer's facility under partial backlogging.

\section{Appendix A.}

The first and second partial derivatives of the function $\mathrm{TC}$ with respect to $t_{1}, t_{2}, t_{3}, t_{4}$, and $t_{6}$ are as follows:

$$
\begin{aligned}
& \frac{\partial \mathrm{TC}}{\partial t_{1}}=\frac{\left(c_{h}+\lambda_{0} \mathrm{e}^{-\eta \zeta} c_{p}\right)\left(\frac{\mathrm{e}^{2 \eta \zeta}(p-d)\left(\lambda_{0} \mathrm{e}^{-\eta \zeta}-\lambda_{0} \mathrm{e}^{\left.-\eta \zeta-\lambda_{0} \mathrm{e}^{-\eta \zeta t_{1}}\right)}\right.}{\lambda_{0}^{2}}+\frac{a e^{2 \eta \zeta}(p-d)\left(-\lambda_{0} \mathrm{e}^{-\eta \zeta}+\lambda_{0} \mathrm{e}^{\left.-\eta \zeta-\lambda_{0} \mathrm{e}^{-\eta \zeta_{t_{1}}}\right)}\right.}{\lambda_{0}^{2}}\right)}{t_{6}} \\
& \frac{\partial \mathrm{TC}}{\partial t_{2}}=\frac{\left(c_{h}+\lambda_{0} \mathrm{e}^{-\eta \zeta} c_{p}\right)\left(\frac{a e^{2 \eta \zeta}(p-d)\left(\lambda_{0} \mathrm{e}^{-\eta \zeta}-\lambda_{0} \mathrm{e}^{\left.-\eta \zeta-\lambda_{0} \mathrm{e}^{-\eta \zeta t_{2}}\right)}\right.}{\lambda_{0}^{2}}+\frac{b e^{2 \eta \zeta}(p-d)\left(\lambda_{0} \mathrm{e}^{\left.-\eta \zeta-\lambda_{0} \mathrm{e}^{-\eta \zeta t_{2}}-\lambda_{0} \mathrm{e}^{-\eta \zeta}\right)}\right)}{\lambda_{0}^{2}}\right)}{t_{6}} \\
& \frac{\partial \mathrm{TC}}{\partial t_{3}}=\frac{\left(c_{h}+\lambda_{0} \mathrm{e}^{-\eta \zeta} c_{p}\right)\left(\frac{b e^{2 \eta \zeta}(p-d)\left(\lambda_{0} \mathrm{e}^{-\eta \zeta}-\lambda_{0} \mathrm{e}^{\left.-\eta \zeta-\lambda_{0} \mathrm{e}^{-\eta \zeta_{t_{3}}}\right)}\right.}{\lambda_{0}^{2}}-\frac{d e^{2 \eta \zeta}\left(\lambda_{0} \mathrm{e}^{-\eta \zeta+\lambda_{0} \mathrm{e}^{-\eta \zeta}\left(t_{4}-t_{3}\right)}-\lambda_{0} \mathrm{e}^{-\eta \zeta}\right)}{\lambda_{0}^{2}}\right)}{t_{6}} \\
& \frac{\partial \mathrm{TC}}{\partial t_{4}}=\frac{t_{6} \lambda_{0}^{2} d(p-d) c_{s} 2\left(\frac{t_{4}}{t_{6}}-1\right)-d e^{2 \eta \zeta}\left(\lambda_{0} \mathrm{e}^{-\eta \zeta}-\lambda_{0} \mathrm{e}^{-\eta \zeta+\lambda_{0} \mathrm{e}^{-\eta \zeta}\left(t_{4}-t_{3}\right)}\right)\left(c_{h}+\lambda_{0} \mathrm{e}^{-\eta \zeta} c_{p}\right)}{p t_{6} \lambda_{0}^{2}} \\
& \frac{\partial \mathrm{TC}}{\partial t_{6}}=\frac{d(p-d) c_{s}\left(t_{6}^{2}-t_{4}^{2}\right)}{p t_{6}^{2}}-\frac{c_{0}}{t_{6}^{2}}-\frac{1}{t_{6}^{2}}\left(c_{h}+\lambda_{0} \mathrm{e}^{-\eta \zeta} c_{p}\right)\left[\frac{\mathrm{e}^{2 \eta \zeta}(p-d)\left(\mathrm{e}^{-\lambda_{0} \mathrm{e}^{-\eta \zeta} t_{1}}+\lambda_{0} \mathrm{e}^{-\eta \zeta} t_{1}-1\right)}{\lambda_{0}^{2}}\right. \\
& +\frac{a e^{2 \eta \zeta}(p-d)\left(-\mathrm{e}^{-\lambda_{0} \mathrm{e}^{-\eta \zeta} t_{1}}+\mathrm{e}^{-\lambda_{0} \mathrm{e}^{-\eta \zeta} t_{2}}+\lambda_{0} \mathrm{e}^{-\eta \zeta}\left(t_{2}-t_{1}\right)\right)}{\lambda_{0}^{2}} \\
& +\frac{b e^{2 \eta \zeta}(p-d)\left(-\mathrm{e}^{-\lambda_{0} \mathrm{e}^{-\eta \zeta} t_{2}}+\mathrm{e}^{-\lambda_{0} \mathrm{e}^{-\eta \zeta} t_{3}}+\lambda_{0} \mathrm{e}^{-\eta \zeta}\left(t_{3}-t_{2}\right)\right)}{\lambda_{0}^{2}} \\
& -\frac{d e^{2 \eta \zeta}\left(1-\mathrm{e}^{\lambda_{0} \mathrm{e}^{-\eta \zeta}\left(t_{4}-t_{3}\right)}+\lambda_{0} \mathrm{e}^{-\eta \zeta}\left(t_{4}-t_{3}\right)\right)}{\lambda_{0}^{2}}
\end{aligned}
$$




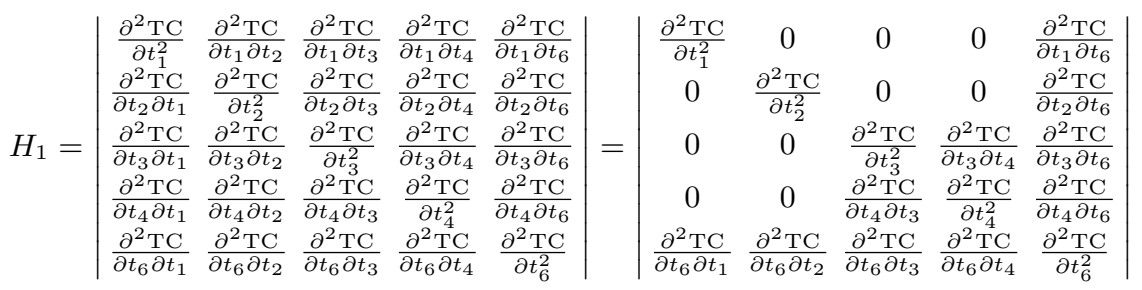

$$
\begin{aligned}
& =\frac{1}{p t_{6}^{7} \lambda_{0}^{2}}\left[d e ^ { - 2 \mathrm { e } ^ { - \zeta \eta } ( 2 \mathrm { e } ^ { \zeta \eta } \zeta \eta + t _ { 1 } \lambda _ { 0 } + t _ { 2 } \lambda _ { 0 } + t _ { 3 } \lambda _ { 0 } ) } ( d - p ) ^ { 2 } ( \mathrm { e } ^ { \zeta \eta } c _ { h } + c _ { p } \lambda _ { 0 } ) ^ { 3 } \left\{(a-1)(a-b)^{2}\right.\right. \\
& \times \mathrm{e}^{\mathrm{e}^{-\zeta \eta}\left(\mathrm{e}^{\zeta \eta} \zeta \eta+t_{1} \lambda_{0}+t_{3} \lambda_{0}\right)}\left(\mathrm{e}^{\mathrm{e}^{-\zeta \eta} t_{2} \lambda_{0}}-1\right)^{2}(d-p)^{2}\left(\mathrm{e}^{\zeta \eta} c_{h}+c_{p} \lambda_{0}\right) \\
& \times\left\{b e^{\zeta \eta+\lambda_{0} \mathrm{e}^{-\zeta \eta}\left(t_{4}-t_{3}\right)} p c_{h}+2 \mathrm{e}^{\zeta \eta}\left(d e^{\lambda_{0} \mathrm{e}^{-\zeta \eta} t_{4}}+b(p-d)\right) c_{s}+b p c_{p} \lambda_{0} \mathrm{e}^{\lambda_{0} \mathrm{e}^{-\zeta \eta}\left(t_{4}-t_{3}\right)}\right\} \\
& +(b-a)\left\{(a-1)^{2} \mathrm{e}^{\mathrm{e}^{-\zeta \eta}\left(\mathrm{e}^{\zeta \eta} \zeta \eta+\lambda_{0} t_{2}+\lambda_{0} t_{3}\right)}\left(\mathrm{e}^{\lambda_{0} \mathrm{e}^{-\zeta \eta} t_{1}}-1\right)^{2}(p-d)^{2}\left(\mathrm{e}^{\zeta \eta} c_{h}+c_{p} \lambda_{0}\right)\right. \\
& \times\left\{b e^{\zeta \eta+\lambda_{0} \mathrm{e}^{-\zeta \eta}\left(t_{4}-t_{3}\right)} p c_{h}+2 \mathrm{e}^{\zeta \eta}\left(d e^{\lambda_{0} \mathrm{e}^{-\zeta \eta} t_{4}}+b(p-d)\right) c_{s}+b e^{\lambda_{0} \mathrm{e}^{-\zeta \eta}\left(t_{4}-t_{3}\right)} p c_{p} \lambda_{0}\right\} \\
& +(a-1) \mathrm{e}^{\lambda_{0} \mathrm{e}^{-\zeta \eta}\left(t_{1}+t_{2}\right)}\left\{2 \mathrm{e}^{\zeta \eta}\left\{d\left(\mathrm{e}^{\lambda_{0} \mathrm{e}^{-\zeta \eta} t_{4}}-\mathrm{e}^{\lambda_{0} \mathrm{e}^{-\zeta \eta} t_{3}}\right)+b\left(\mathrm{e}^{\lambda_{0} \mathrm{e}^{-\zeta \eta} t_{3}}-1\right)(p-d)\right\}^{2}\right. \\
& \times\left(\mathrm{e}^{\zeta \eta} c_{h}+c_{p} \lambda_{0}\right)\left\{p c_{h} \mathrm{e}^{\zeta \eta+\lambda_{0} \mathrm{e}^{-\zeta \eta}\left(t_{4}-t_{3}\right)}+\mathrm{e}^{\zeta \eta}(p-d) c_{s}+p c_{p} \lambda_{0} \mathrm{e}^{\lambda_{0} \mathrm{e}^{-\zeta \eta}\left(t_{4}-t_{3}\right)}\right\} \\
& +\mathrm{e}^{\zeta \eta}\left\{d\left(\mathrm{e}^{\mathrm{e}^{-\zeta \eta} t_{3} \lambda_{0}}+\mathrm{e}^{\mathrm{e}^{-\zeta \eta} t_{4} \lambda_{0}}\right)+b\left(\mathrm{e}^{\mathrm{e}^{-\zeta \eta} t_{3} \lambda_{0}}-1\right)(p-d)\right\}\left(2 d \mathrm{e}^{\mathrm{e}^{-\zeta \eta} t_{4} \lambda_{0}}+b(p-d)\right) \\
& \times\left(\mathrm{e}^{\zeta \eta} c_{h}+c_{p} \lambda_{0}\right)\left\{\mathrm{e}^{\zeta \eta}\left(\mathrm{e}^{\mathrm{e}^{-\zeta \eta}\left(t_{4}-t_{3}\right) \lambda_{0}}-1\right) p c_{h}+\lambda_{0}\left\{p c_{p}\left(\mathrm{e}^{\mathrm{e}^{-\zeta \eta}\left(t_{4}-t_{3}\right) \lambda_{0}}-1\right)+2(p-d) c_{s} t_{4}\right\}\right\} \\
& +2 \mathrm{e}^{\mathrm{e}^{-\zeta \eta} t_{3} \lambda_{0}}(p-d) \lambda_{0}^{2}\left\{b e^{\zeta \eta+\lambda_{0} \mathrm{e}^{-\zeta \eta}\left(t_{4}-t_{3}\right)} p c_{h}+2 \mathrm{e}^{\zeta \eta}\left\{d e^{\mathrm{e}^{-\zeta \eta} t_{4} \lambda_{0}}+b(p-d)\right\} c_{s}+b p c_{p} \lambda_{0} \mathrm{e}^{\lambda_{0} \mathrm{e}^{-\zeta \eta}\left(t_{4}-t_{3}\right)}\right\} \\
& \times\left\{c_{0}+\frac{d(p-d) c_{s} t_{4}^{2}}{p}+\frac{\left(c_{h}+\mathrm{e}^{-\zeta \eta} c_{p} \lambda_{0}\right)}{\lambda_{0}^{2} \mathrm{e}^{2 \zeta \eta}}\left\{(p-d)\left(\mathrm{e}^{-\mathrm{e}^{-\zeta \eta} t_{1} \lambda_{0}}+\mathrm{e}^{-\zeta \eta} t_{1} \lambda_{0}-1\right)\right.\right. \\
& +a(p-d)\left\{\mathrm{e}^{-\mathrm{e}^{-\zeta \eta} t_{1} \lambda_{0}}+\mathrm{e}^{-\mathrm{e}^{-\zeta \eta} t_{2} \lambda_{0}}+\mathrm{e}^{-\zeta \eta}\left(t_{2}-t_{1}\right) \lambda_{0}\right\}+b(p-d)\left\{\mathrm{e}^{-\mathrm{e}^{-\zeta \eta} t_{3} \lambda_{0}}+\mathrm{e}^{-\zeta \eta}\left(t_{3}-t_{2}\right) \lambda_{0}+\mathrm{e}^{-\mathrm{e}^{-\zeta \eta} t_{2} \lambda_{0}}\right\} \\
& \left.\left.\left.\left.\left.\left.+d\left(1+\mathrm{e}^{\lambda_{0} \mathrm{e}^{-\zeta \eta}\left(t_{4}-t_{3}\right)}+\lambda_{0} \mathrm{e}^{-\zeta \eta}\left(t_{4}-t_{3}\right)\right)\right\}\right\}\right\}\right\}\right\}\right]>0 \text {. }
\end{aligned}
$$

Because $\left(\mathrm{e}^{\lambda_{0} \mathrm{e}^{-\zeta \eta} t_{4}}-\mathrm{e}^{\lambda_{0} \mathrm{e}^{-\zeta \eta} t_{3}}\right)>0,\left(\mathrm{e}^{\lambda_{0} \mathrm{e}^{-\zeta \eta} t_{3}}-1\right) \geq 0,\left(\mathrm{e}^{\mathrm{e}^{-\zeta \eta} t_{3} \lambda_{0}}-1\right) \geq 0,\left(\mathrm{e}^{\lambda_{0} \mathrm{e}^{-\zeta \eta}\left(t_{4}-t_{3}\right)}-1\right) \geq 0$, $\left(\mathrm{e}^{\lambda_{0} \mathrm{e}^{-\zeta \eta}\left(t_{4}-t_{3}\right)}-1\right) \geq 0,\left(\mathrm{e}^{-\mathrm{e}^{-\zeta \eta} t_{1} \lambda_{0}}+\mathrm{e}^{-\zeta \eta} t_{1} \lambda_{0}-1\right) \geq 0$ when $p>d, 1<a<b, 0<\lambda_{0}<1,0<t_{1}<t_{2}<$ $t_{3}<t_{4}<t_{6}$ and $\zeta \in[0, \bar{\zeta}]$. The values of $H_{1}$ is verified in Figure A.1.

Therefore, for the solution of $t_{1}, t_{2}, t_{3}, t_{4}$ and $t_{6}$ it is mandatory to consider the following:

$$
\begin{aligned}
& \frac{\partial \mathrm{TC}}{\partial t_{1}}=0, \frac{\partial \mathrm{TC}}{\partial t_{2}}=0, \frac{\partial \mathrm{TC}}{\partial t_{3}}=0, \frac{\partial \mathrm{TC}}{\partial t_{4}}=0 \text { and } \frac{\partial \mathrm{TC}}{\partial t_{6}}=0 \\
& \text { s.t. } 0<t_{1}<t_{2}<t_{3}<t_{4}<t_{6} .
\end{aligned}
$$




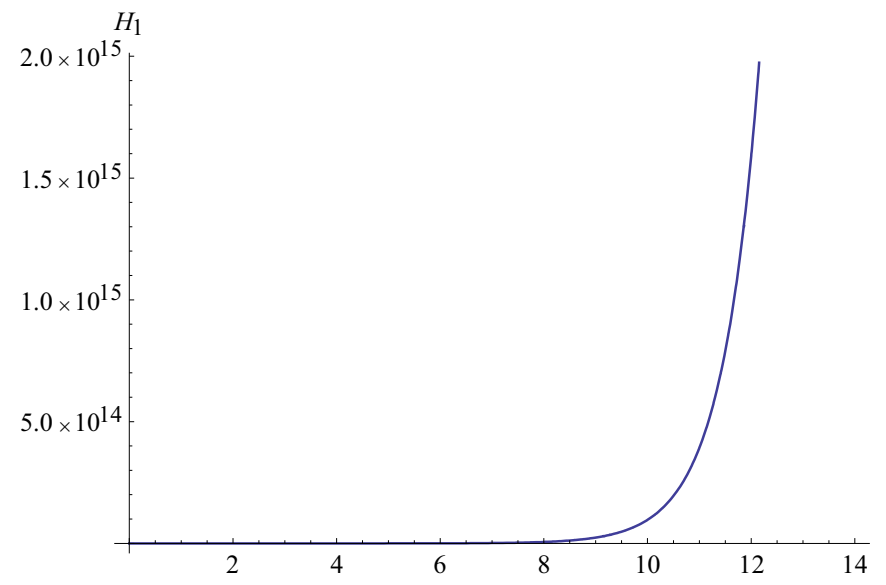

Figure A.1. $H_{1}$ with respect to $\zeta$ when $t_{1}=0.237589, t_{2}=0.263965, t_{3}=2.63737, t_{4}=$ $3.51353, t_{6}=3.62889$.

\section{Appendix B.}

The first and second partial derivatives of the total function $\operatorname{TC}\left(t_{4}, t_{6}, \zeta\right)$ with respect to $\zeta$ are given by:

$$
\frac{\partial \mathrm{TC}}{\partial \zeta}=L\left(t_{1}, t_{2}, t_{3}, t_{4}, t_{6}, \zeta\right)
$$

where

$$
\begin{aligned}
& L\left(t_{1}, t_{2}, t_{3}, t_{4}, t_{6}, \zeta\right) \\
& =1-\frac{1}{t_{6}} \lambda_{0} \mathrm{e}^{-\eta \zeta_{\eta c_{p}}}\left[\frac{\mathrm{e}^{2 \eta \zeta}(p-d)\left(\mathrm{e}^{-\lambda_{0}} \mathrm{e}^{-\eta \zeta_{t_{1}}}+\lambda_{0} \mathrm{e}^{\left.-\eta \zeta_{t_{1}}-1\right)}\right.}{\lambda_{0}^{2}}\right.
\end{aligned}
$$

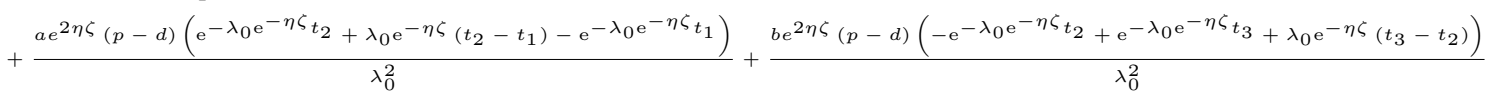

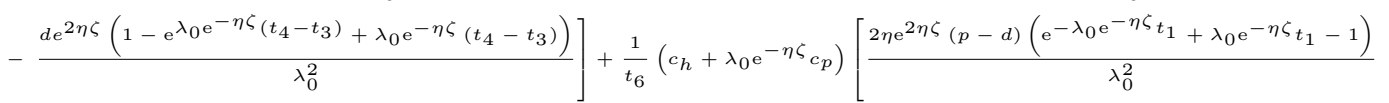

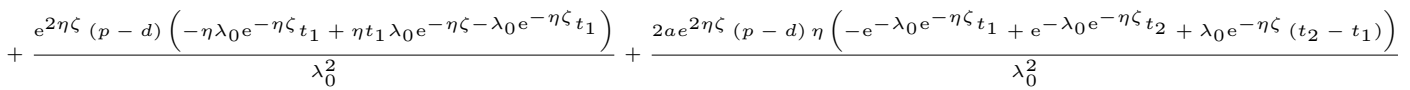

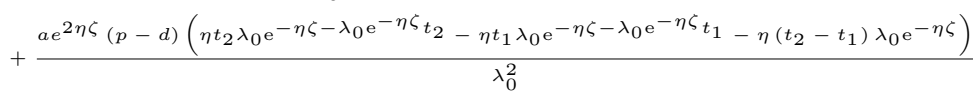

$$
\begin{aligned}
& +\frac{2 b e^{2 \eta \zeta}(p-d) \eta\left(\mathrm{e}^{-\lambda_{0}} \mathrm{e}^{-\eta \zeta} t_{3}+\lambda_{0} \mathrm{e}^{-\eta \zeta}\left(t_{3}-t_{2}\right)-\mathrm{e}^{-\lambda_{0} \mathrm{e}^{-\eta \zeta_{t}}}\right)}{\lambda_{0}^{2}}
\end{aligned}
$$

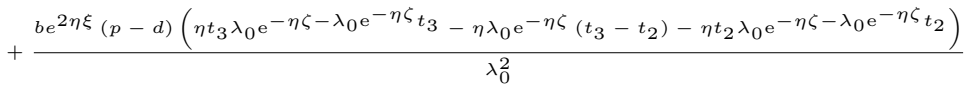

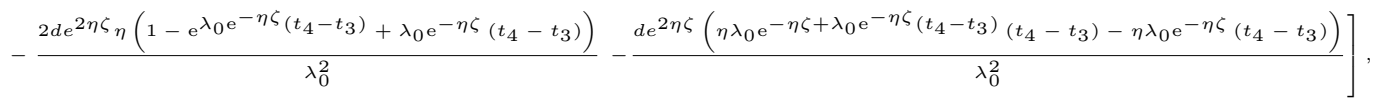

and

$$
\frac{\partial^{2} \mathrm{TC}}{\partial \zeta^{2}}>0
$$

For simplicity, set $H(\zeta)=L\left(t_{1}, t_{2}, t_{3}, t_{4}, t_{6}, \zeta\right)$ and define 
$\Delta_{3}\left(t_{1}, t_{2}, t_{3}, t_{4}, t_{6}\right)=\left.H(\zeta)\right|_{\zeta=0}=L\left(t_{1}, t_{2}, t_{3}, t_{4}, t_{6}, \zeta\right), \Delta_{4}\left(t_{1}, t_{2}, t_{3}, t_{4}, t_{6}\right)=\left.H(\alpha)\right|_{\zeta=\bar{\zeta}}=L\left(t_{1}, t_{2}, t_{3}, t_{4}, t_{6}, \zeta\right)$. It is obvious that $H^{\prime}(\zeta)>0$. So $H(\zeta)$ is strictly increasing in $\zeta$.

(1) If $\Delta_{3}\left(t_{1}, t_{2}, t_{3}, t_{4}, t_{6}\right) \leq 0, H(\zeta) \leq 0$ and $\forall \zeta \in[0, \bar{\zeta}]$ then $\operatorname{TC}\left(t_{1}, t_{2}, t_{3}, t_{4}, t_{6}, \zeta\right)$ is increasing in $\zeta \in[0, \bar{\zeta}]$. Consequently the optimal preservation cost is $\zeta^{*}=0$.

(2) If $\Delta_{4}\left(t_{1}, t_{2}, t_{3}, t_{4}, t_{6}\right) \geq 0, H(\zeta) \geq 0$ and $\forall \zeta \in[0, \bar{\zeta}]$ then $\operatorname{TC}\left(t_{1}, t_{2}, t_{3}, t_{4}, t_{6}, \zeta\right)$ is decreasing in $\zeta \in[0, \bar{\zeta}]$. Therefore the optimal preservation cost is $\zeta^{*}=\bar{\zeta}$.

(3) If $\Delta_{3}\left(t_{1}, t_{2}, t_{3}, t_{4}, t_{6}\right)>0$ and $\Delta_{4}\left(t_{1}, t_{2}, t_{3}, t_{4}, t_{6}\right)<0$ then according to the intermediate value theorem, there exists a unique value $\zeta \in[0, \bar{\zeta}]$ to satisfy $H\left(\zeta^{*}\right)=0$, that is,

$$
L\left(t_{1}, t_{2}, t_{3}, t_{4}, t_{6}, \zeta\right)=0
$$

\section{REFERENCES}

[1] M. Bakker, J. Riezebos and R.H. Teunter, Review of inventory systems with deterioration since 2001. Eur. J. Oper. Res. 221 (2012) 275-284.

[2] Z.T. Balkhi, On the global optimal solution to an integrated inventory system with general time varying demand, production and deterioration rates. Eur. J. Oper. Res. 114 (1999) 29-37.

[3] Z.T. Balkhi and L. Benkherouf, A production lot size inventory model for deteriorating items and arbitrary production and demand rates. Eur. J. Oper. Res. 92 (1996) 302-309.

[4] L.E. Cárdenas-Barrón, The derivation of EOQ/EPQ inventory models with two backorders costs using analytic geometry and algebra. Appl. Math. Model. 35 (2011) 2394-2407.

[5] H.J. Chang and C.Y. Dye, An EOQ model for deteriorating items with time varying demand and partial backlogging. J. Oper. Res. Soc. 50 (1999) 1176-1182.

[6] R.P. Covert and G.C. Philip, An EOQ model for items with Weibull distribution deterioration. AIIE Trans. 5 (1973) $323-326$.

[7] C.Y. Dye, The effect of preservation technology investment on a non-instantaneous deteriorating inventory model. Omega 41 (2013) 872-880.

[8] C.Y. Dye and T.P. Hsieh, An optimal replenishment policy for deteriorating items with effective investment in preservation technology. Eur. J. Oper. Res. 218 (2012) 106-112.

[9] P.M. Ghare and G.F. Schrader, A model for exponentially decaying inventory. J. Ind. Eng. 14 (1963) $238-243$.

[10] S.K. Goyal and B.C. Giri, Recent trends in modeling of deteriorating inventory. Eur. J. Oper. Res. 134 (2001) 1-16.

[11] S.K. Goyal and B.C. Giri, The production-inventory problem of a product with time varying demand, production and deterioration rates. Eur. J. Oper. Res. 147 (2003) 549-557.

[12] S.K. Goyal and A. Gunasekaran, An integrated production-inventory-marketing model for deteriorating items. Comput. Ind. Eng. 28 (1995) 755-762.

[13] T.P. Hsieh and C.Y. Dye, A production-inventory model incorporating the effect of preservation technology investment when demand is fluctuating with time. J. Comput. Appl. Math. 239 (2013) 25-36.

[14] P.H. Hsu, H.M. Wee and H.M. Teng, Preservation technology investment for deteriorating inventory. Int. J. Prod. Econ. 124 (2010) 388-394.

[15] L. Janssen, T. Claus and J. Sauer, Literature review of deteriorating inventory models by key topics from 2012 to 2015 . Int. J. Prod. Econ. 182 (2016) 86-112.

[16] Y.P. Lee and C.Y. Dye, An inventory model for deteriorating items under stock-dependent demand and controllable deterioration rate. Comput. Ind. Eng. 63 (2012) 474-482.

[17] G. Liu, J. Zhang and W. Tang, Joint dynamic pricing and investment strategy for perishable foods with price-quality dependent demand. Ann. Oper. Res. 226 (2015) 397-416.

[18] R.B. Misra, Optimum production lot size model for a system with deteriorating inventory. Int. J. Prod. Res. 13 (1975) $495-505$.

[19] F. Raafat, Survey of literature on continuously deteriorating inventory models. J. Oper. Res. Soc. 42 (1991) $27-37$.

[20] S. Saha, I. Nielsen and I. Moon, Optimal retailer investments in green operations and preservation technology for deteriorating items. J. Clean. Prod. 140 (2017) 1514-1527.

[21] B. Sarkar and I. Moon, An EPQ model with inflation in an imperfect production system. Appl. Math. Comput. 217 (2011) 6159-6167.

[22] Y.C. Tsao, Joint location, inventory, and preservation decisions for non-instantaneous deterioration items under delay in payments. Int. J. Syst. Sci. 47 (2016) 572-585.

[23] G. Viji and K. Karthikeyan, An economic production quantity model for three levels of production with Weibull distribution deterioration and shortage. Ain Shams Eng. J. 9 (2018) 1481-1487.

[24] H.M. Wee, Economic production lot size model for deteriorating items with partial back-ordering. Comput. Ind. Eng. 24 (1993) $449-458$.

[25] G.A. Widyadana and H.M. Wee, An economic production quantity model for deteriorating items with multiple production setups and rework. Int. J. Prod. Econ. 138 (2012) 62-67. 
[26] K.S. Wu, L.Y. Ouyang and C.T. Yang, An optimal replenishment policy for non-instantaneous deteriorating items with stockdependent demand and partial backlogging. Int. J. Prod. Econ. 101 (2006) 369-384.

[27] C.T. Yang, C.Y. Dye and J.F. Ding, Optimal dynamic trade credit and preservation technology allocation for a deteriorating inventory model. Comput. Ind. Eng. 87 (2015) 356-369.

[28] J. Zhang, Z. Bai and W. Tang, Optimal pricing policy for deteriorating items with preservation technology investment. J. Ind. Manage. Optim. 10 (2014) 1261-1277.

[29] J. Zhang, G. Liu, Q. Zhang and Z. Bai, Coordinating a supply chain for deteriorating items with a revenue sharing and cooperative investment contract. Omega 56 (2015) 37-49.

[30] J. Zhang, Q. Wei, Q. Zhang and W. Tang, Pricing, service and preservation technology investments policy for deteriorating items under common resource constraints. Comput. Ind. Eng. 95 (2016) 1-9. 